\title{
Piperacillin-associated pulmonary infiltrates with eosinophilia: A case report
}

\author{
Olivia Ling-I Tseng MSc MD, John Thomas Kelsall MDCM FRCPC ABIM, Pearce George Wilcox MD FRCPC
}

\author{
OL-I Tseng, JT Kelsall, PG Wilcox. Piperacillin-associated \\ pulmonary infiltrates with eosinophilia: A case report. Can \\ Respir J 2010;17(2):e24-e26.
}

\begin{abstract}
A case of pulmonary infiltrates with eosinophilia attributed to piperacillin/ tazobactam therapy is described. A 54-year-old woman was treated for a suspected severe urinary tract infection with piperacillin/tazobactam. Four days later, she developed fever, chills, shortness of breath and intermittent chest pains. Eosinophilia was noted in peripheral blood and, subsequently, on bronchoalveolar lavage. Transbronchial biopsy showed tissue infiltrates with eosinophilia. No evidence of bacterial, fungal and parasitic infection, or vasculitis was observed. Her symptoms and peripheral eosinophilia subsided after drug discontinuation and oral prednisone treatment. Piperacillin is an extended-spectrum penicillin antibiotic prescribed for moderate to severe infections. The common adverse reactions to piperacillin include nausea, vomiting, diarrhea and rash. Pulmonary infiltrates with eosinophilia is a rare adverse reaction, but one that may result in significant morbidity. Physicians should be aware of this rare but important adverse reaction to piperacillin.
\end{abstract}

Key Words: Antibiotics; Drug-associated pulmonary infiltrates with eosinophilia; Eosinophilic lung disease; Lung; Piperacillin; Pulmonary infiltrates with eosinophilia

\section{CASE PRESENTATION}

The present report describes two hospital admissions that occurred less than $24 \mathrm{~h}$ apart. To provide a clearer time frame, these two hospital admissions are described as one event. The key information (eg, medications, peripheral absolute eosinophil counts and allergic reactions) are summarized in Figure 1. A 54-year-old woman of Serbian descent presented to the emergency room with fever and chills after a diagnostic cystoscopy. Empirical treatment with piperacillin/tazobactam (pip/tazo) was started for a suspected urinary tract infection. Her first chest $\mathrm{x}$-ray (CXR) was normal, without any patchy consolidation. She was admitted to the general internal medicine ward. On day 2, she became short of breath. As part of her evaluation, a computed tomography scan showed diffuse thickening of the interlobular septae and subpleural opacity/ patchy consolidation in both lungs. On day 4, eosinophilia (absolute eosinophil count $1.9 \times 10^{9} / \mathrm{L}$ ) was noticed. Her CXR showed basilar, predominantly linear densities with some patchy consolidation. On day 5 , she developed a metallic taste in her mouth. A presumptive diagnosis of transient bacteremia after cystoscopy was made. No cultures for blood, urine, sputum or stool were positive. On day 6, she was discharged with oral azithromycin and ciprofloxacin.

\author{
Des infiltrats pulmonaires à éosinophiles \\ associés à la pipéracilline: Un rapport de cas
}

Les auteurs décrivent un cas d'infiltrats pulmonaires à éosinophiles attribués à une thérapie à la pipéracilline et au tazobactam. Une femme de 54 ans ayant une grave infection urinaire présumée a reçu un traitement à la pipéracilline et au tazobactam. Quatre jours plus tard, elle s'est mise à faire de la fièvre, à avoir des frissons, à être essoufflée et à souffrir de douleurs thoraciques intermittentes. On a constaté la présence d'éosinophiles dans le sang périphérique et, par la suite, dans le lavage bronchoalvéolaire. La biopsie transbronchique a révélé la présence d'infiltrats tissulaires à éosinophiles. On n'a observé aucuns signes d'infection bactérienne, fongique ou parasitaire ou de vasculite. Les symptômes et l'éosinophilie périphérique se sont résorbés après l'arrêt de la pharmacothérapie et un traitement à la prednisone par voie orale. La pipéracilline est un antibiotique à large spectre du groupe de la pénicilline, prescrit en cas d'infections modérées à graves. Les effets indésirables courants de la pipéracilline sont les nausées, les vomissements, la diarrhée et les éruptions. Les infiltrats pulmonaires à éosinophiles sont une réaction indésirable rare qui peut entraîner une importante morbidité. Les médecins devraient connaître cet effet indésirable à la pipéracilline, car il est rare mais grave

Within $24 \mathrm{~h}$ of discharge, she returned to the emergency room with severe shortness of breath, cough, intermittent chest pains, fever and chills. Physical examination revealed a welldeveloped woman in acute respiratory distress. Her body temperature was normal, with a blood pressure of $136 / 89 \mathrm{mmHg}$, a heart rate of 88 beats/min and a respiratory rate of 30 breaths/min. Her breathing was laboured, with the use of accessory muscles and intercostal indrawings. Oxygen $\left(\mathrm{O}_{2}\right)$ saturation was $96 \%$ on $10 \mathrm{~L} / \mathrm{min} \mathrm{O}_{2}$ by nasal prongs. Her heart sounds were normal, with no murmurs. A respiratory examination showed bilateral basal crackles without wheezes.

She had a medical history of type 2 diabetes, hypertension, dyslipidemia, hypothyroidism and left bundle branch block. She smoked one pack of cigarettes per day from 19 to 45 years of age and from 52 to 54 years of age. She stopped smoking approximately one year previously and has not resumed. She returned to her home town in Serbia three months before the present admission. She has owned a cat for one year. She operates a cleaning business and works as a cashier. She does not have contact with pulmonary toxins or irritants. Her medications before day 1 included rosuvastatin $30 \mathrm{mg} /$ day, atenolol $100 \mathrm{mg} /$ day, levothyroxine $100 \mu \mathrm{g} /$ day, esomeprazole $80 \mathrm{mg} /$ day and metformin $1000 \mathrm{mg} /$ day. 
On day 6, when she returned to the emergency room, laboratory investigations revealed leukocytosis, with a white blood cell (WBC) count of $17.6 \times 10^{9} / \mathrm{L}$ (normal range $4 \times 10^{9} / \mathrm{L}$ to $11 \times 10^{9} / \mathrm{L}$ ). Her peripheral absolute eosinophil count was $1.8 \times 10^{9} / \mathrm{L}$ (normal $0 \times 10^{9} / \mathrm{L}$ to $0.7 \times 10^{9} / \mathrm{L}$ ). Her lactate level was $2.5 \mathrm{mmol} / \mathrm{L}$ (normal $0.5 \mathrm{mmol} / \mathrm{L}$ to $2.1 \mathrm{mmol} / \mathrm{L}$ ), which increased to $3.7 \mathrm{mmol} / \mathrm{L}$ one day later. On $10 \mathrm{~L}$ of $\mathrm{O}_{2}$ by mask, her arterial blood gas $\mathrm{pH}$ was 7.42 (normal $\mathrm{pH} 7.36$ to 7.44), partial pressure of $\mathrm{O}_{2} 78 \mathrm{mmHg}$ (normal greater than $75 \mathrm{mmHg}$ ), partial pressure of carbon dioxide $32 \mathrm{mmHg}$ (normal $35 \mathrm{mmHg}$ to $45 \mathrm{mmHg}$ ), and calculated bicarbonate of $21 \mathrm{mmol} / \mathrm{L}$ (normal $21 \mathrm{mmol} / \mathrm{L}$ to $25 \mathrm{mmol} / \mathrm{L}$ ). The test results were normal to borderline abnormal for renal function, liver function, electrolytes and electrocardiogram. Her CXR revealed small bilateral pleural effusions, with basilar, predominantly linear densities and patchy consolidation.

On day 7, the patient was readmitted to the general internal medicine ward. Infection was suspected by the care team due to leukocytosis, elevated lactate levels, abnormal CXR and recent history of diagnostic cystoscopy. Intravenous pip/tazo was started because the patient appeared to respond well to this treatment during her previous admission. Hypoxemia was partially improved with bronchodilators, and her $\mathrm{O}_{2}$ demand dropped to $4 \mathrm{~L} / \mathrm{min}$ to $6 \mathrm{~L} / \mathrm{min}$ by mask. However, she developed a numb and swollen tongue, swollen lips and itchy maculopapular rashes on both palms. On day 8, a respirologist and an infection specialist were consulted on account of suspected infection, eosinophilia and abnormal CXR. Pip/tazo was discontinued and her antibiotics were switched to intravenous imipenem/cilastatin due to possible drug reactions to pip/tazo. Thoracentesis was not performed because the pleural effusions were judged to be too small on ultrasonography. Between days 9 and 12 , the patient still needed oxygen $2 \mathrm{~L} / \mathrm{min}$ to $4 \mathrm{~L} / \mathrm{min}$ by nasal prongs, with significant exertional dyspnea. Itchy maculopapular rashes also appeared on the dorsal part of both ankles. All noninvasive tests including markers for autoimmune diseases and extensive investigation for parasitic/ bacterial/fungal infections showed negative results.

On day 14, she still had significant exertional dyspnea and a fibre optic bronchoscopy was performed by the respirologist. No cytological findings of malignancy were seen. The bronchial alveolar lavage (BAL) revealed a red blood cell count of $53 \times 10^{6} / \mathrm{L}$ and a WBC count of $13 \times 10^{6} / \mathrm{L}$. The differential of WBC was 35\% eosinophils with $56 \%$ macrophages. Acid-fast stain smear, tuberculosis culture, and routine bacterial and fungal culture tests were negative. The transbronchial biopsy showed benign pulmonary parenchyma with interstitial eosinophils, an occasional alveolar eosinophil and some airspace hemosiderin macrophages. Pip/tazo-associated pulmonary infiltrates with eosinophilia (PIE) was suspected.

Daily oral prednisone $40 \mathrm{mg}$ was initiated on day 16 due to diagnosis of PIE and significant exertional dyspnea. Her peripheral absolute eosinophil count dropped to zero three days later. Shortness of breath, cough and exercise endurance significantly improved one week later. She was capable of climbing seven flights of stairs without rest compared with two flights of stairs before oral prednisone treatment. She was discharged from the hospital and followed up regularly at the respirologist's office. After four weeks of oral prednisone, radiological improvement was observed. The oral prednisone was

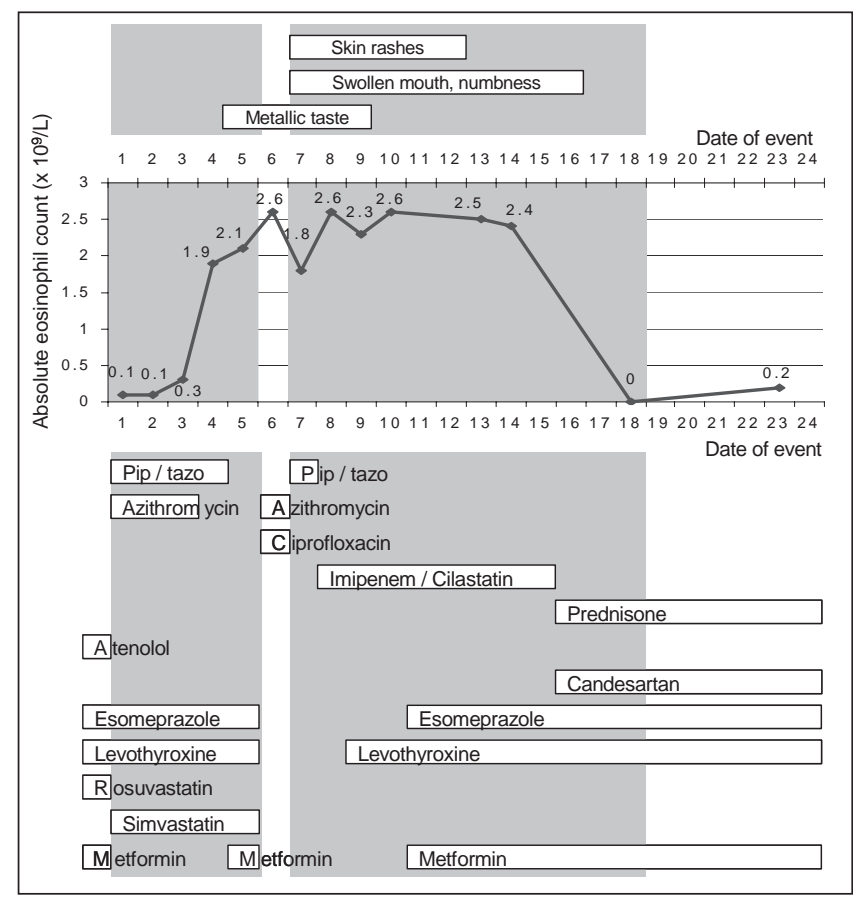

Figure 1) Summary of medications, allergic reactions and peripheral absolute eosinophil counts in the patient. The grey area represents hospital admissions. Pip/tazo Piperacillin/tazobactam

tapered progressively and completed uneventfully over a period of three months. After cessation of oral prednisone, there was no evidence of recurrence and peripheral absolute eosinophil counts remained normal. A further penicillin skin allergy test was performed by an immunologist. The patient showed a positive reaction to penicillin ( 1 million units $/ \mathrm{mL})$ at 1:10 dilution. The positive penicillin test result indicated a high possibility of allergic reaction to piperacillin due to cross-reactivity.

\section{DISCUSSION}

PIE or pulmonary eosinophilia is a heterogeneous group of disorders associated with eosinophilia within the lung parenchyma and/or blood eosinophilia. To diagnose PIE, the following criteria should be fulfilled: peripheral eosinophilia (absolute eosinophil count of greater than $0.6 \times 10^{9} / \mathrm{L}[1]$ ) with pulmonary opacities in radiological or tomographic images, lung tissue infiltration with eosinophilia on biopsy and eosinophilia in BAL (usually greater than 25\% [2]). Common causes of PIE include drug- and toxin-associated eosinophilic lung diseases, parasitic infection, fungal infection, idiopathic acute/ chronic eosinophilic pneumonia and Churg-Strauss syndrome. In the present case, the patient presented with peripheral eosinophilia (up to $2.6 \times 10^{9} / \mathrm{L}$ ), eosinophilia (35\% eosinophil) in BAL and eosinophil infiltrates in lung parenchyma on transbronchial biopsies. Her laboratory results did not substantiate the possibilities of vasculitis, connective tissue disease, or parasitic and fungal infection. Chronic eosinophilia pneumonia was not likely given the initial normal chest radiography. All evidence led us to the conclusion of drug-associated PIE. A medication chart is presented in Figure 1. Among her medications, pip/tazo (3-5) and simvastatin (6) had been reported with an adverse reaction of PIE. Simvastatin was less likely the cause of PIE in the present case because peripheral eosinophil 
counts increased to even higher levels after simvastatin was discontinued. Based on the positive penicillin test, temporal relationship, allergic symptoms and her history, the immunologist concluded that piperacillin was the most likely medication to have caused PIE.

Drug-associated PIE was first identified by Liebow and Carrington (7) in 1969. Currently, more than 100 medications have been associated with PIE. Among these medications, antibiotics (eg, nitrofurantoin, ampicillin, penicillin, clarithromycin and sulfonamides) and nonsteroidal anti-inflammatory drugs are the most common causes. Other common medications include angiotensin-converting enzyme inhibitors, anticonvulsants, antidepressants, beta-blockers and amiodarone (8). A detailed drug list with literature references can be found at the website <www.pneumotox.com>, which is maintained by Groupe d'Etudes de la Pathologic Pulmonaire Iatrogène.

The mechanism of drug-associated PIE remains unclear. One possible explanation is the activation of T helper 2 (Th2) lymphocytes by antigen-presenting cells (alveolar macrophages). Activated Th2 lymphocytes release interleukin-5, which leads to eosinophil production, chemotaxis to the lung and degranulation (9).

Clinical symptoms of PIE range from asymptomatic cough with fever and dyspnea to severe hypoxemia. Systemic allergic reaction, such as skin rash, may coexist. Differential diagnosis of drug-associated PIE includes acute/chronic eosinophilic pneumonia, fungal infection, parasitic infection and vasculitis. The diagnosis of drug-associated PIE is often a major challenge. Clinically, drug-associated PIE is supported if the following four criteria are met: temporal relationship between suspected drug, clinical symptoms and lung disease, eosinophilia in lung tissue or BAL, no other possible causes identified or improvement of symptoms after suspect drug discontinuation (9). Laboratory evaluation is rarely helpful in diagnosing drug-associated PIE. Peripheral eosinophilia and elevated immunoglobulin E levels are usually present but not specific in drug-associated PIE cases because they also present in many other diseases. CXRs in drug-associated PIE demonstrate nonspecific findings including pleural effusion, reticulonodular densities, consolidation and hilar adenopathy (10). In a study of 22 patients with drugassociated PIE syndrome, thin-section computed tomography also showed nonspecific findings including airspace consolidation and peripheral predominance $(30 \%)$, and bronchial wall thickening and bronchiectasis (5\%) (11). The gold standard method to diagnose drug-associated PIE is with a drug provocation/challenge test. However, a formal drug provocation/challenge test is limited due to ethical issues, equipment and facility availability, and possible severe consequences of irreversible pulmonary dysfunction (12). The key treatment for drug-associated PIE syndrome is early recognition and discontinuation of possible causative medications. Oral prednisone is used in more severe cases with confirmed diagnosis and hypoxemia, or significant respiratory distress. All physicians should be aware of this rare adverse reaction when they prescribe common medications including nonsteroidal antiinflammatory drugs and antibiotics.

ACKNOWLEDGEMENTS: The authors thank Dr Donald Stark for performing the penicillin allergy tests.

\section{REFERENCES}

1. Tefferi A, Blood eosinophilia: A new paradigm in disease classification, diagnosis, and treatment. Mayo Clin Proc 2005;80:75-83.

2. Allen JN, Davis WB. Eosinophilic lung diseases. Am J Respir Crit Care Med 1994;150(5Pt1):1423-38.

3. Ibrahim AS, Ghadban WK, Arrayes M. Eosinophilic pleural effusion due to cloxacillin and piperacillin/tazobactum. $<$ http://www.hmc.org.qa/qmj/qmj2006/JUNE2006/case/case2.htm> (Accessed July 2009).

4. Nakamura T, Kawanami Y, Yoshimoto M, et al. [Case of severe eosinophilic pneumonia, induced by several antibiotics, requiring mechanical ventilation]. Nihon Kokyuki Gakkai Zasshi 2006;44:695-700.

5. Yamamoto T, Tanida T, Ueta E, et al. Pulmonary infiltration with eosinophilia (PIE) syndrome induced by antibiotics, PIPC and TFLX during cancer treatment. Oral Oncol 2001;37:471-5.

6. Yoshioka S, Mukae H, Ishii H, et al. [A case of drug-induced pneumonia possibly associated with simvastatin.] Nihon Kokyuki Gakkai Zasshi 2005;43:600-4.

7. Liebow AA, Carrington CB. The eosinophilic pneumonias. Medicine (Baltimore) 1969;48:251-85.

8. Solomon J, Schwarz M. Drug-, toxin- and radiation therapy-induced eosinophilic pneumonia. Semin Respir Crit Care Med 2006;27:192-7.

9. Allen JN. Drug-induced eosinophilic lung disease. Clin Chest Med 2004:25:77-88.

10. Jeong YJ, Kim KI, Seo IJ, et al. Eosinophilic lung diseases: A clinical, radiologic, and pathologic overview. Radiographics 2007;27:617-37; discussion 37-9.

11. Schelhorn J, Hofer L, Syrbe G, Polzer U. [Drug-induced eosinophilic pneumonia]. Nervenarzt 2008;79:696-8.

12. Romano A, Demoly P. Recent advances in the diagnosis of drug allergy. Curr Opin Allergy Clin Immunol 2007;7:299-303. 


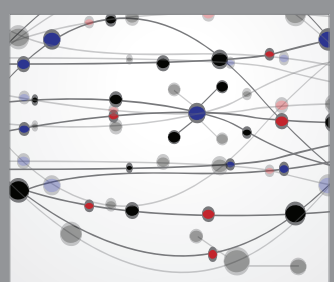

The Scientific World Journal
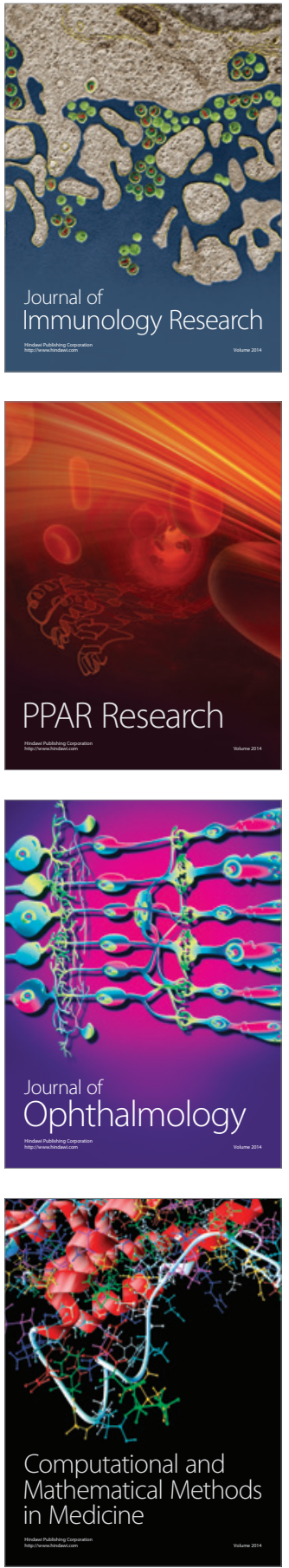

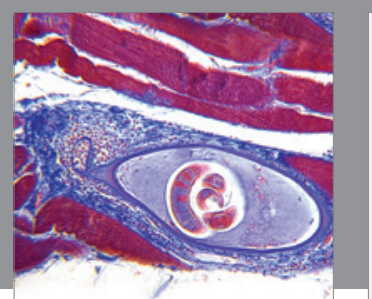

Gastroenterology Research and Practice

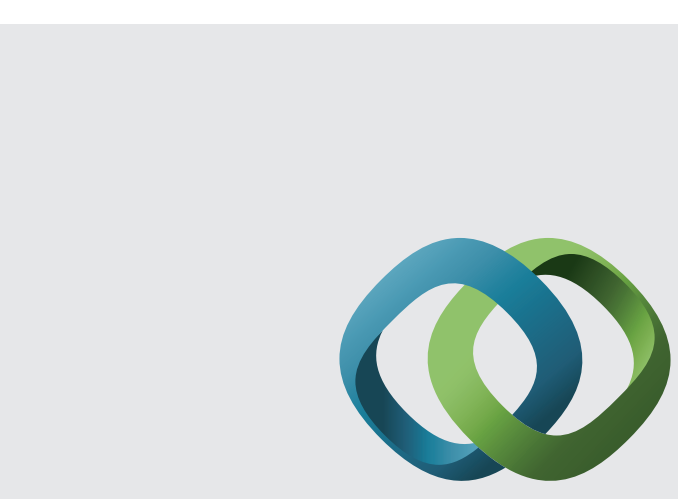

\section{Hindawi}

Submit your manuscripts at

http://www.hindawi.com
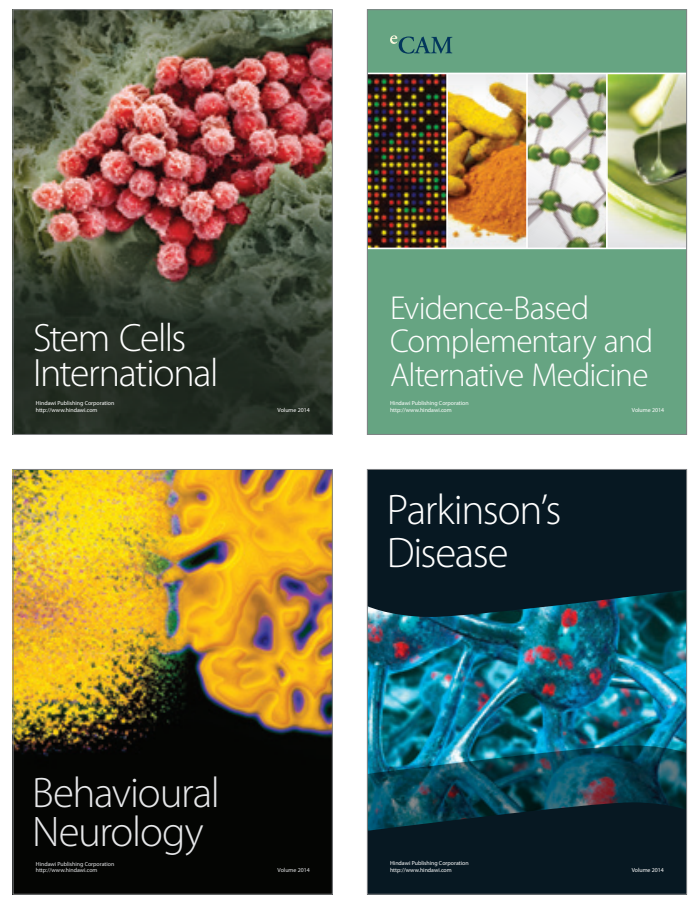
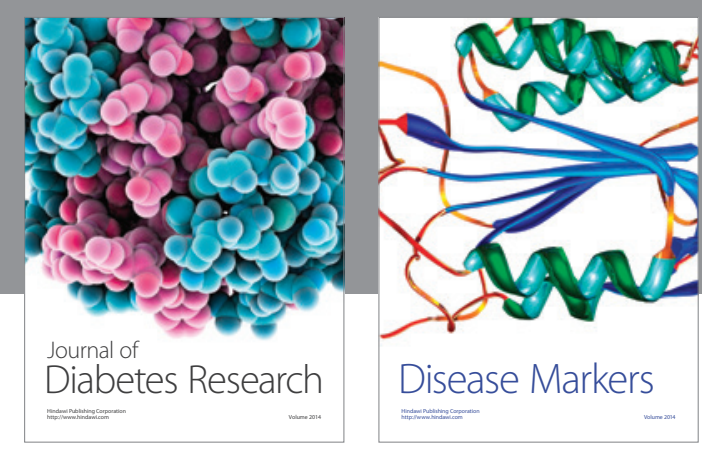

Disease Markers
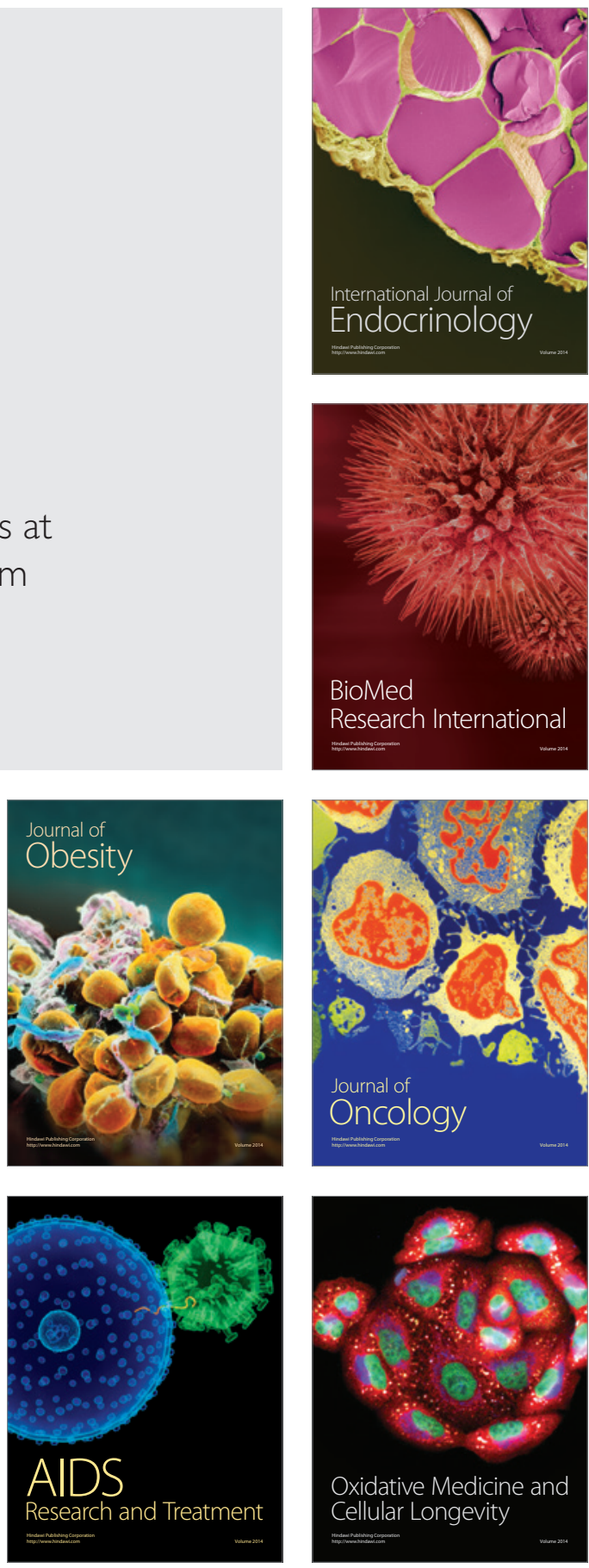